\title{
Plugging of Parallel-Tube Devices with Fluid Foods
}

\section{Steven Brandon $\mathrm{C}^{1}$ and Paul Dawson $\mathrm{L}^{2 *}$}

${ }^{1}$ Membrane Application Services, SC, USA

${ }^{2}$ Department of Food Science and Human Nutrition, Clemson University, Clemson, SC, USA

\begin{abstract}
Plugging often occurs when fluid foods are processed in parallel-tube devices (e.g., tubular heat exchangers and membrane filtration modules, especially when fluids are concentrated). Plugging reduces productivity by reducing performance and causing downtime to remove the plug. The cause of plugging is explained here for the first time and a means of avoiding it is described. Plugging rarely occurs during normal operation while fluid food is being pumped through the tubes, but rather when the tubes are flushed with water, e.g., prior to routine cleaning. The study identified two prerequisites for plugging to occur: tubes must have unequal resistances to flow and the fluid food must possess a yield stress that exceeds a value which depends on the device geometry.
\end{abstract}

Keywords: Parallel; Plugging; Microfiltration; Membrane; Tubular; Heat exchanger; Yield stress; Non-Newtonian; Herschel-Bulkley; Tomato paste; Carbopol

\section{List of Symbols}

\begin{tabular}{|c|c|c|}
\hline Symbol & & Units \\
\hline $\mathrm{R}^{2}$ & Coefficient of Determination & --- \\
\hline$m$ & Consistency Index & --- \\
\hline$\rho$ & Density & $\mathrm{kg} / \mathrm{m}^{3}$ \\
\hline$D$ & Diameter & $\mathrm{m}$ \\
\hline$L_{e}$ & Entrance Length & $\mathrm{m}$ \\
\hline$n$ & Flow Behavior Index & --- \\
\hline$n^{\prime}$ & Flow Behavior Index; approximation & --- \\
\hline $\mathrm{L}$ & Length & $\mathrm{m}$ \\
\hline$l$ & Length of Column of Flushing Fluid & $\mathrm{m}$ \\
\hline$P_{1}$ & Pressure at Tube Inlet & $\mathrm{Pa}$ \\
\hline$P_{2}$ & Pressure at Tube Outlet & $\mathrm{Pa}$ \\
\hline$\Delta P_{i}$ & Pressure Difference at Time Increment; i & $\mathrm{Pa}$ \\
\hline$\Delta P_{1}$ & Pressure Difference; Tube 1 & $\mathrm{~Pa}$ \\
\hline$\Delta P_{2}$ & Pressure Difference; Tube 2 & $\mathrm{~Pa}$ \\
\hline$\Delta P_{3}$ & Pressure Difference; Tube 3 & $\mathrm{~Pa}$ \\
\hline$\Delta P_{4}$ & Pressure Difference; Tube 4 & $\mathrm{~Pa}$ \\
\hline$K$ & Resistance Coefficient; Overall & -- \\
\hline$\dot{\gamma}$ & Shear Rate & $1 / \mathrm{s}$ \\
\hline$\dot{\gamma}_{w}$ & Shear Rate at the Wall & $1 / \mathrm{s}$ \\
\hline$\tau$ & Shear Stress & $\mathrm{Pa}$ \\
\hline$\tau_{w}$ & Shear Stress at the Wall & $\mathrm{Pa}$ \\
\hline V & Velocity; Average & $\mathrm{m} / \mathrm{s}$ \\
\hline$\mu$ & Viscosity & Pa-s \\
\hline$\mu_{a p p}$ & Viscosity; Apparent & $\mathrm{Pa}-\mathrm{s}$ \\
\hline$Q_{1}$ & Volumetric Flow Rate; Tube 1 & $\mathrm{~m}^{3} / \mathrm{s}$ \\
\hline$Q_{2}$ & Volumetric Flow Rate; Tube 2 & $\mathrm{~m}^{3} / \mathrm{s}$ \\
\hline$Q_{3}$ & Volumetric Flow Rate; Tube 3 & $\mathrm{~m}^{3} / \mathrm{s}$ \\
\hline$Q_{4}$ & Volumetric Flow Rate; Tube 4 & $\mathrm{~m}^{3} / \mathrm{s}$ \\
\hline$Q_{\text {TOTAL }}$ & Volumetric Flow Rate; Total & $\mathrm{m}^{3} / \mathrm{s}$ \\
\hline$\tau_{0}$ & Yield Stress & $\mathrm{Pa}$ \\
\hline$\tau_{B}$ & Yield Stress; Bingham & $\mathrm{Pa}$ \\
\hline
\end{tabular}

\section{Introduction}

\section{Problem statement}

When fluid foods are concentrated in parallel-tube microfiltration modules the modules are frequently found to have one or more tubes plugged with solid paste-like material necessitating costly downtime to remove the plugs. In fact a whole industry has developed plans for plug removal [1]. The cause for this plugging phenomenon has not been well understood but has generally been believed to occur while very viscous fluids were being pumped through parallel channels. The thesis of the current study is that plugging of parallel-tube devices including both concentrating devices e.g. microfiltration membrane modules and evaporators and non-concentrating devices e.g. tubular heat exchangers occurs when yield stress fluids are flushed from the tubes with water. If this plugging phenomenon can be more clearly understood gradual dilution of viscous fluids during the end of processing runs could prevent the costly downtime and maintenance required when plugging occurs. If a pump is stopped and restarted while parallel tubes are filled with a yield-stress fluid the imposed pressure difference overcomes the yield stress and flow recommences. However if water rather than yieldstress fluid is pumped into flow channels that are initially filled with yield-stress fluid it is possible that one or more of the parallel channels will clear i.e. have all of the yield-stress fluid displaced with water before the other channels are cleared. The applied pressure difference across all parallel channels will then fall to that of the water-filled channel a level which may be insufficient to maintain flow of the yield-stress material remaining in the incompletely cleared channels.

If water is added to the yield-stress fluid moving through the parallel-tube flow device diluting the yield-stress fluid it is possible to displace the yield-stress fluid from the tubes without forming plug however the dilution must be gradual.

\section{Plugging}

In this paper the term "plugging" refers to blockage of a tube with yield-stress material which does not move even when flow is observed

*Corresponding author: Paul Dawson L, Department of Food Science and Human Nutrition, Clemson University, Clemson, SC 29634, USA, Tel: 864-656-1138; E-mail: pdawson@clemson.edu

Received April 19, 2016; Accepted May 11, 2016; Published May 17, 2016

Citation: Steven Brandon C, Paul Dawson L (2016) Plugging of Parallel-Tube Devices with Fluid Foods. J Food Process Technol 7: 587. doi:10.4172/21577110.1000587

Copyright: @ 2016 Steven Brandon C, et al. This is an open-access article distributed under the terms of the Creative Commons Attribution License, which permits unrestricted use, distribution, and reproduction in any medium, provided the original author and source are credited. 
in neighboring tubes. Of course plugging may be caused by incorrect operation of equipment, for example the capture of solid objects in the tubes due to inadequate pre-filtration or in the case of filtration modules by failing to circulate the process fluid resulting in over concentration of process fluid in individual tubes.

Plugging of parallel-tubes devices results in isolation of the plugged tubes from the process reducing the performance and altering flow characteristics of the device. However since neither the loss of performance nor the change in flow characteristics are sensitive methods of plug detection the presence of plugged tubes is usually confirmed only by visual inspection.

\section{Rheology background}

Yield stress: Yield stress is defined as the minimum shear stress required initiating flow [2]. While the existence of yield stress has been challenged by arguing that all materials will flow when exposed to a shear stress given sufficient time from a practical standpoint there is little doubt that yield stress is an engineering reality $[3,4]$.

Apparent yield stress: The term apparent yield stress has been introduced to cover cases where there is very little flow at low shear stress. Frequently it is not possible to decide whether a true yield stress exists or not. Therefore some workers prefer to refer to an 'apparent yield stress' which is an operational parameter and its evaluation involves extrapolation of data to zero shear rate often the value depending upon the range of data being used to evaluate it [5].

Bingham yield stress: Rao [6] cites Michaels and Bolger [7] who introduces the concept of the Bingham yield stress $\tau_{B}$ which is obtained by extrapolation of only the linear portion of the shear stress versus shear rate data to zero shear rates. The Bingham yield stress is part of the total yield stress at higher shear rates. For apple sauce the Bingham yield stress was found to be very close to the static yield stresses measured directly using the vane method [8].

Apparent slip velocity: Many inhomogeneous mixtures which contain suspended particles exhibit slip velocity at the wall due to migration of these particles away from the region of highest shear near the wall and toward regions of lower shear which for flow in tubes is at the center line of the tube [9]. The relative depletion of particles in the region near the wall referred to as the lubrication layer [10] results in lower apparent viscosity and reduced yield stress in the fluid near the wall. The consequence of this flow behavior is that bulk motion of the mixture occurs at shear stress levels below the apparent yield stress of the mixture. Since even in cases in which slip occurs the velocity of fluid in contact with the wall still approaches zero at the wall interface this phenomenon is here referred to as apparent slip velocity.

Meeker et al. [10] state that the magnitude of the apparent slip velocity depends on the shear stress. They describe three regimes of slip. First when the shear stress is at least $50 \%$ larger than the yield stress i.e. $\tau_{w /} \tau_{0} \geq 1.5$ slip is negligible compared to the bulk flow. Secondly when the shear stress exceeds the yield stress by less than $50 \%$ i.e. when $1<\tau_{w}$ $\tau_{0}<1.5$ slip becomes significant and the total deformation of the paste results from a combination of bulk flow and slip. Thirdly when the shear stress is less than or equal to the yield stress i.e. $\tau_{w /} \tau_{0} \leq 1$ the bulk flow is negligible and the apparent motion is entirely due to the slipping of the paste. Apparent slip velocity has been measured using techniques such as magnetic resonance imaging [11] and ultrasonic flow meters [12,13] which do not disturb the velocity profiles of these fluids.
Herschel-Bulkley model: The Herschel-Bulkley model Equation (1) below may be used to describe the rheological behavior of a broad range of fluid types including Newtonian pseudo plastic dilatant and Bingham plastic fluids.

$$
\tau=\tau_{0}+m \dot{\gamma}^{n}
$$

The Herschel-Bulkley model states that the shear stress that must be applied to a fluid to impart a given resulting shear rate in the fluid equals the sum of the fluid's yield stress and the product of the consistency index $m$ and the shear rate raised to the power of the flow behavior index $n$ [14].

The applicability of the Herschel-Bulkley model to a variety of fluid foods is supported by Aguilera and Stanley [15] who stated that "In many food liquids and suspensions $\tau$ versus $\bar{Y}$ data do not fit a straight line (i.e. the viscosity does not remain constant) but rather $\tau$ varies with $\bar{Y}$ so that an apparent viscosity $\mu_{\text {app }}$ has to be defined at each $\bar{Y}$. Moreover the relationship may not start at the origin which entails that some materials will not flow unless a critical stress or yield value $\tau_{0}$ is reached after which they will flow like liquids."

Tubular viscometry: The shear rate at the wall for non-Newtonian fluids flowing in tubes is calculated using Equation (2) the RabinowitschMooney equation

$$
\dot{\gamma}_{w}=\left[\frac{3 n^{\prime}+1}{4 n^{\prime}}\right] \frac{8 V}{D}
$$

Where $n^{\prime}$ is the point slope of the $\log (\tau)$ vs. $\log (8 \mathrm{~V} / \mathrm{D})$ plot [16]. Since the average velocity in the tube is easily calculated from the measured volumetric flow rates determination of shear rate is not complex.

The formula for calculating shear stress at the wall for fluids flowing in tubes is derived from a force balance on a cylindrical element of fluid in the tube. This formula is given in Equation (3) below.

$$
\tau=\frac{\left(P-P_{2}\right)}{4(L / D)}
$$

Here the relevant pressure difference is only that portion of the pressure difference imparted by frictional losses due to viscous flow rather than the measured total pressure.

\section{Fluid mechanics background}

Pressure differences: As shown in Equation (4) below the measured total pressure difference across each tube results in part from frictional pressure losses due to viscous flow and in part from momentum-change pressure losses due to changes in velocity and direction of the fluid at the entrance and exit of each parallel tube.

$$
\Delta P_{\text {TOTAL }}=\Delta P_{\text {FRICTION }}+\Delta P_{M C}
$$

Since the shear stress at the wall results only from the frictional pressure difference it is necessary to subtract the momentum-change pressure difference from the measured total pressure difference to obtain the frictional pressure difference.

The momentum-change pressure difference is given by the overall resistance coefficient $K$ for each parallel tube using Equation (5).

$$
\Delta P_{M C}=K \frac{\rho V^{2}}{2}
$$

Since momentum-change pressure difference is due only to changes in the flow velocity and direction it is independent of fluid properties 
other than density. This means that the overall resistance coefficient determined while pumping a Newtonian fluid such as water through the tubes can be considered to be identical to that when non-Newtonian fluids are flowing through the tubes. This is supported by Carrère and René [17] who cite Midoux [18] stating that "For non-Newtonian fluids in the case of power law fluids with $0.1<n<2$ the resistance coefficient can be considered as not differing from the Newtonian value with $n$ $=1$. " Having determined the overall resistance coefficient for each parallel tube in the test rig with water it is a simple matter to calculate the frictional pressure difference by subtracting the momentum-change pressure difference from the measured total pressure difference.

Flow in parallel tubes: For flow through parallel tubes the total volumetric flow rate equals the sum of the volumetric flow rates in each tube i.e.

$$
Q_{\text {TOTAL }}=Q_{1}+Q_{2}+Q_{3}+Q_{4} .
$$

Also the pressure difference across each parallel tube is the same i.e.

$$
\Delta P_{\text {TOTAL }}=\Delta P_{1}=\Delta P_{2}=\Delta P_{3}=\Delta P_{4}
$$

This thesis was tested using an experimental approach in which flow of fluid foods was observed in four parallel transparent tubes [19]. Four fluids were studied: water glycerin Carbopol gel and tomato paste. These fluids were selected for reference characterization high viscosity without yield stress a well-defined yield stress model fluid and a representative yield stress food material respectively.

\section{Materials and Methods}

\section{Experimental test rig}

The test rig shown in Figure 1 was constructed from PVC and stainless steel (SS) piping. The four parallel tubes were transparent PVC Schedule 40 pipes with $21.2 \mathrm{~mm}$ inside diameter and $2.03 \mathrm{~m}$ length. The test fluids were moved through the tubes using a sanitary pump (Model 130 Waukesha Universal series positive-displacement rotary pump with a 5-to-1 variable speed controller). Steady temperature was maintained during the tests with a single-tube heat exchanger of 34.9 $\mathrm{mm}$ inside diameter $3.05 \mathrm{~m}$ length and $0.335 \mathrm{~m}^{2}$ of heat transfer area.

To enable data to be collected at low velocities a diaphragm valve was used to control the bypass of some of the flow directly to the suction of the pump. A sanitary plug valve (labeled "MCV" in Figure 1) allowed selection between a once-through mode used when flushing the test rig with water and recirculation mode used to allow test fluids to be pumped continuously through the test rig.

Flow rates from 2.37 litres to 189 liters per minute were measured using a magnetic flow meter (Hersey ${ }^{\circledR} 25.4 \mathrm{~mm}$ Balanced Electrode Plane magnetic flow meter with a Model 100 Indicator $\pm 0.5 \%$ accuracy). Lower flow rates were measured by timing over a premeasured distance the movement of small bubbles in the central plug region of the Carbopol gel or of particles near the surface of the tomato paste (when moving in slip flow at stresses below the yield stress of the paste). Pressure was measured using two ENFM $^{\circledR}$ Bourdon-tube pressure gauges $(0-413 \mathrm{kPa} . \pm 1.0 \%$ accuracy glycerin filled diaphragm protected) at headers upstream and downstream of the four parallel tubes. To improve accuracy of the upstream pressure measurement an additional pressure gauge was installed at the upstream header (sanitary Chicago Stainless Equipment ${ }^{\circledR}$ Bourdon-tube pressure gauge $(0-690 \mathrm{kPa}$ $\pm 1.5 \%$ accuracy glycerin filled diaphragm protected). Temperature was measured using an inline bi-metallic thermometer $\left(-18^{\circ} \mathrm{C}\right.$ to $\left.121^{\circ} \mathrm{C}\right)$. The $\mathrm{pH}$ of the test fluids was measured using an inline double-junction

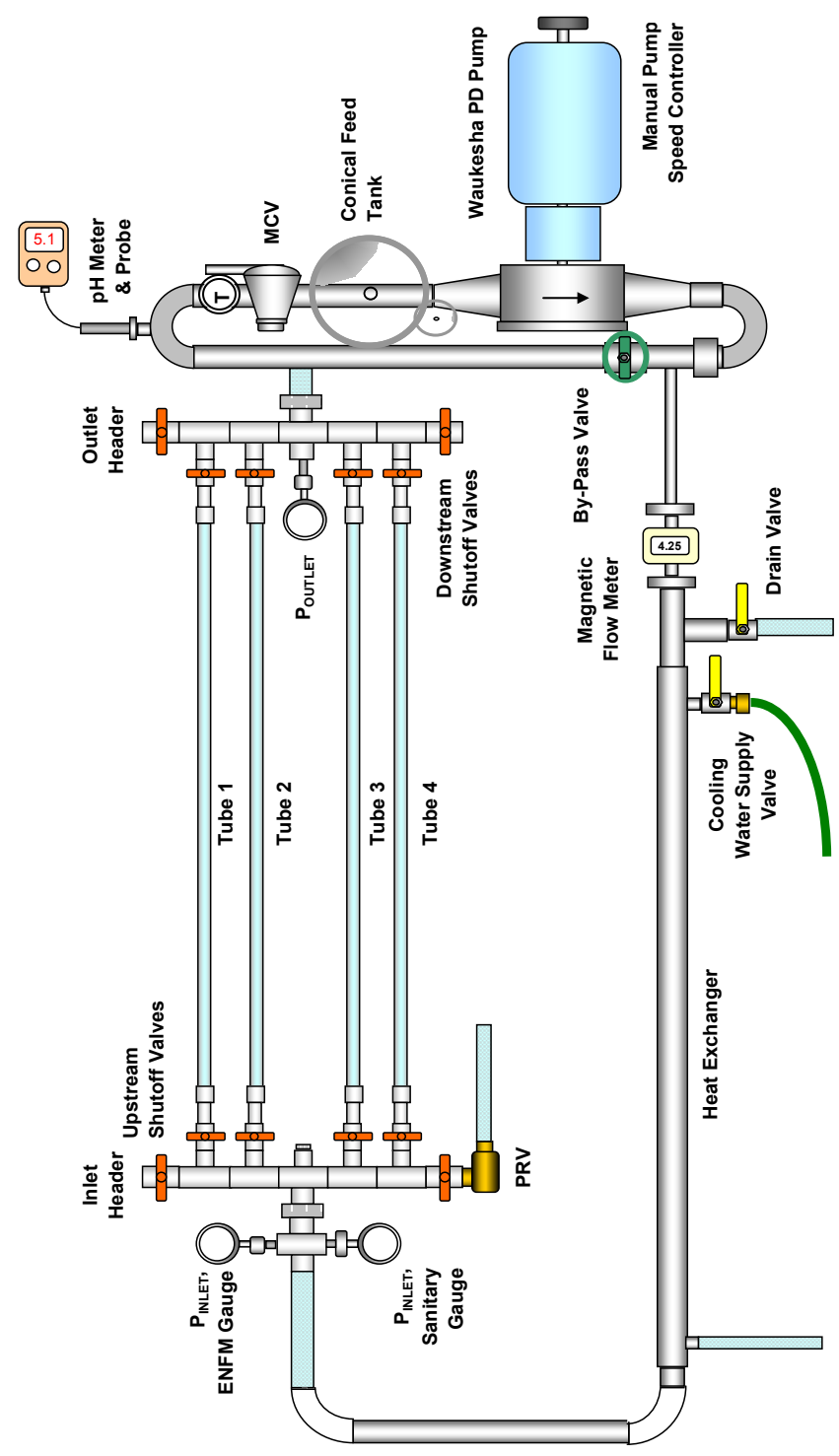

Figure 1: Overhead view diagram of the test rig.

glass $\mathrm{pH}$ electrode sensor with a CPVC housing connected to a digital $\mathrm{pH}$ meter (Fisher ${ }^{\mathbb{B}}$ Model No. 107). Test fluid added to or removed from the test rig was weighed using Ohaus ${ }^{\circledR} 0-50 \mathrm{~kg}$ electronic scales with Model No. I10 digital indicator.

Viscous test fluids were supplied to the test rig via a 19-L conical tank. Water was supplied from a 95-L tank. The $\mathrm{pH}$ of the $1.5 \%$ Carbopol gel was raised from $\mathrm{pH} 2.8$ to $\mathrm{pH} 5$ using $25 \% \mathrm{NaOH}$ introduced into the system via a $500-\mathrm{mL}$ SS funnel installed in the pump suction line.

\section{Test fluids}

Flushing tests were conducted on each of two fluids with non-zero yield stresses and one viscous Newtonian fluid as a control. At least three replicate tests for performed for each fluid.

a) Cold-break tomato paste was supplied by Campbell Soup Research and Development Dixon California USA in aseptically packaged bags collected from their processing line on 25 July 2003. Each bag contained approximately $2 \mathrm{~kg}$ of paste 
with solids content ranging from 41 to $43 \%$. Several bags were required to fill the test rig. Distilled water was mixed with the paste diluting the solids content to about $32 \%$ solids. Dilution was necessary to fill the test rig with the paste. To conserve the limited supply of tomato paste paste was recovered from the test rig when the test rig piping was cleared prior to each plugging test. In subsequent tests the recovered paste which had been stored cold was mixed with previously unused paste to refill the test rig.

b) Canned hot-break Dei Fratelli Italian Style tomato paste was used in one additional test Test T7.

c) Carbopol $^{\circledR} 940$ (Noveon Inc. Cleveland Ohio USA) cross-linked polyacrylic acid food thickener was mixed dissolved in distilled water to prepare a $1.5 \% \mathrm{w} / \mathrm{w}$ aqueous solution. This fluid was used to fill the test rig and then adjusted from $\mathrm{pH} 2.8$ to $\mathrm{pH} 5.0$ \pm 0.5 by the addition of $25 \% \mathrm{NaOH}$ solution. The homogeneity of $\mathrm{pH}$ in the Carbopol gel was insured by pumping the solution through the test rig for several minutes while monitoring the $\mathrm{pH}$ and confirming that the lack of measurable changes in $\mathrm{pH}$ in the test fluid being pumped past the $\mathrm{pH}$ probe.

d) Glycerin was selected as the control fluid because it has a high viscosity but lacks a yield stress.

\section{Test procedure}

For each test fluid the following tasks were performed. First the rheological properties of each fluid were determined by the following procedure.

I. The pressure difference from the upstream to the downstream header was recorded over a range of flow rates.

II. The flow rate in the pipes was controlled by varying the rotational speed of the pump and by adjusting the feed by-pass valve (BPV). Volumetric flow rates above 2.5 liters per minute were read with the magnetic flow meter while flow rates below this rate were measured by timing the motion of air bubbles in the uniform-velocity plug-flow region of the flow.

III. Shear stress at the wall and shear rate at the wall were calculated from this data.

IV. The consistency index $m$ the flow behavior index $n$ and the yield stress of the test fluid were also determined.

The pump and all lines except for the four parallel transparent PVC pipes were flushed with filtered water. The valves connecting the parallel pipes to the downstream header were closed and the pipe drain valves were opened to direct flow from the pipes into buckets placed under each pipe's drain valve. The pump was restarted at low speed with the BPV open. The BPV was then closed to force all flow from the positivedisplacement pump into the upstream header and pipe(s) flushed clear with water were recorded. The interface position between the test fluid and water in each plugged pipe was then recorded. This procedure was repeated at least twice for each test fluid (at least 3 repetitions).

\section{Results and Discussion}

\section{Glycerin}

A linear plot of shear stress versus shear rate for the glycerin data Figure 2 reveals the expected proportional relationship characteristic of Newtonian fluids. The reported viscosity of glycerin at the same

\section{Glycerin - Rheological Data}

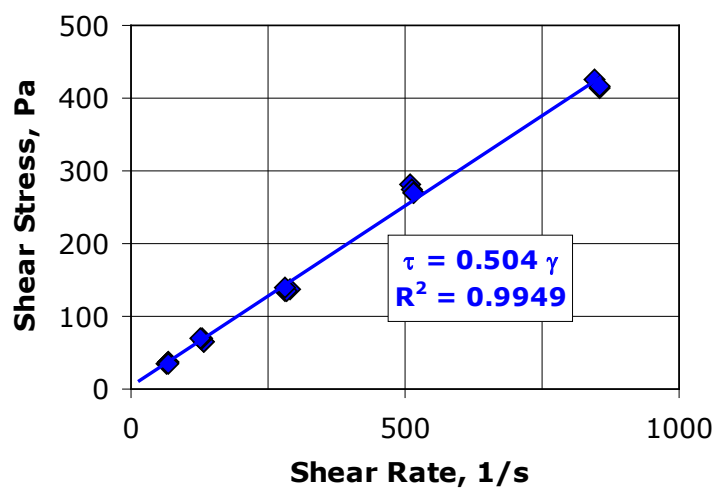

Figure 2: Glycerin rheological data.

temperature $30^{\circ} \mathrm{C}$ is $629 \mathrm{mPa}-\mathrm{s}$ [20] compared to $504 \mathrm{mPa}-\mathrm{s}$ in the present study.

The viscosity of glycerin is extremely sensitive to the presence of water [21]. Even though care was taken to minimize the presence of water as the test rig was filled with glycerin the lower than expected measured viscosity likely resulted from a small amount of residual water in the test rig. Nevertheless the glycerin was found to be a Newtonian fluid with no yield stress.

\section{Carbopol gel}

Figure 3 shows for each Carbopol 940 gel shear rate plotted against the difference between the shear stress at the wall and the yield stress of each test fluid. The formulas indicate the Herschel-Bulkley model formulas for each test. For both the Carbopol gel and the tomato paste a yield stress value was selected to provide the best curve fit of the data. This was achieved by selecting yield stress values that maximized the $\mathrm{R}^{2}$ values of the power-law curve fit formulas. Combining this selected yield stress with the consistency index and the flow behavior index gives the complete Herschel-Bulkley formula for each of the test fluids. The values of the three Herschel-Bulkley parameters: yield stress consistency index and flow behavior index were determined for each Carbopol gel sample and are presented in Table 1.

The higher $\mathrm{R}^{2}$ values obtained with the Herschel-Bulkley model than with the pseudo-plastic model as shown in Table 1 indicate that the Herschel-Bulkley model more accurately describes the flow behavior of this test fluid. This result agrees with Curran et al. [22] who report that for a $1.48 \%$ Carbopol gel "steady-shear data were shown to be fitted well by the Herschel-Bulkley model". For the three different tests run on Carbopol gel the close similarity in rheological parameters is believed to result from using gel prepared in a single large batch prior to running the series of tests on this fluid.

\section{Tomato paste}

As shown in Figure 4 greater variation in rheological properties was observed in the tomato paste. This variation is not surprising considering the fact that the batches of paste used in each test were prepared by mixing aseptically-packaged paste samples collected at different times in the tomato processing plant. These samples ranged from $41 \%$ to $43 \%$ solids.

Another factor that increased variation between the rheological properties of each batch of tomato paste was dilution of the paste 
Citation: Steven Brandon C, Paul Dawson L (2016) Plugging of Parallel-Tube Devices with Fluid Foods. J Food Process Technol 7: 587. doi:10.4172/2157-7110.1000587

Page 5 of 7

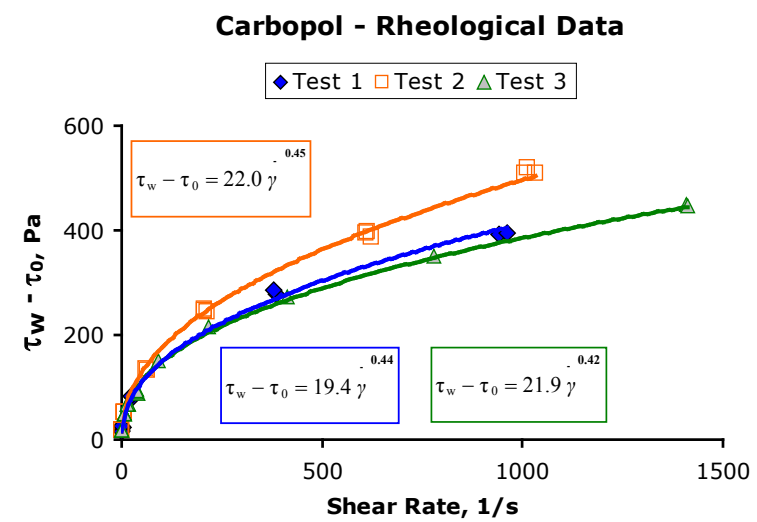

Figure 3: Carbopol gel rheological data.

\begin{tabular}{|c|c|c|c|c|c|c|c|}
\hline \multirow{2}{*}{ Test } & \multicolumn{3}{|c|}{ Pseudoplastic Model } & \multicolumn{4}{c|}{ Herschel-Bulkley Model } \\
\cline { 2 - 8 } & $\mathrm{m}$ & $\mathrm{n}$ & $\mathrm{R}^{2}$ & $\mathrm{~T}_{0}$ & $\mathrm{~m}$ & $\mathrm{n}$ & $\mathrm{R}^{2}$ \\
\cline { 2 - 8 } & $\mathrm{Pa}-\mathrm{s}^{\mathrm{n}}$ & --- & --- & $\mathrm{Pa}$ & $\mathrm{Pa}-\mathrm{s}^{\mathrm{n}}$ & --- & --- \\
\hline $\mathrm{C} 1$ & 116.8 & 0.199 & 0.967 & 103.8 & 19.47 & 0.442 & 0.998 \\
\hline $\mathrm{C} 2$ & 101.9 & 0.234 & 0.962 & 85.5 & 22 & 0.451 & 0.999 \\
\hline C3 & 115.2 & 0.189 & 0.926 & 106.4 & 21.91 & 0.415 & 0.994 \\
\hline
\end{tabular}

Table 1: Carbopol gel rheological parameters.

Tomato Paste - Rheogram

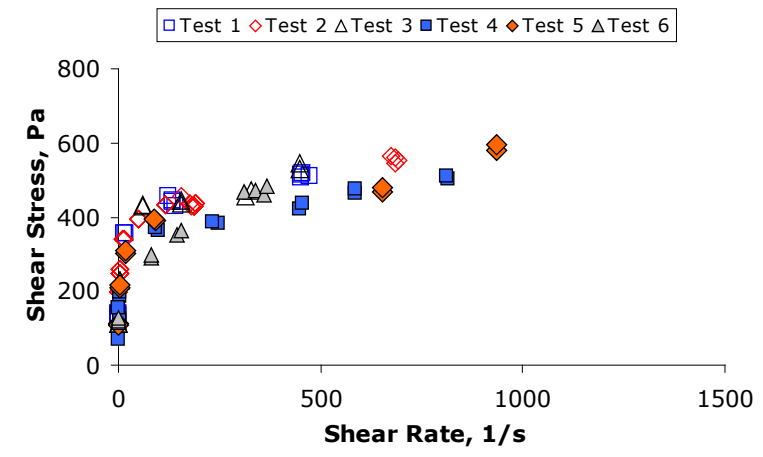

Figure 4: Tomato paste rheological data.

samples by adding distilled water equal to $30 \%$ of the mass of tomato paste. This dilution was necessary to reduce their apparent viscosity sufficiently to permit the paste to be drawn from the feed cone into the suction of the Waukesha PD pump. Despite the variation in rheological properties the objective of observing the behavior of a semi-solid food material as it is flushed from parallel tubes was achieved with the tomato paste.

As was done for the Carbopol rheological data a yield stress value was selected which gave the best fit $\left(\mathrm{R}^{2}\right.$ nearest 1.0) of the data using the Herschel-Bulkley model. The values of the three Herschel-Bulkley parameters: yield stress consistency index and flow behavior index were determined for each tomato paste sample and are presented in Table 2 . Note that in all but two test cases no improvement in the fit of the data was obtained by applying a yield stress to the curve-fit formula. In other words these tomato paste samples appeared to behave as pseudo-plastic fluids lacking a dynamic yield stress. As reported in the literature tomato pastes are known to possess a static yield stress. This is supported by direct observation of the tomato paste in the current study (Figure 5).
Tomato ketchup a product based on tomato paste has been reported to possess a yield stress that is reduced from the initial static yield stress of an undisturbed sample to a lower dynamic yield stress after the paste has been exposed to shear stress resulting in breakdown of structure. In the rheological tests carried out in the current study only the apparent dynamic yield stress of each tomato paste sample was measured [23].

In the plugging tests where some motion is initiated as flushing water advances into the parallel tubes there may be some breakdown of structure but likely much less than during measurement of the rheological parameters when the paste is repeatedly pumped through the tubes for an extended time. During plugging tests the paste remained motionless in the tubes for a short time which may have allowed some recovery of structure and static yield stress which was not measured in the current study.

Since the static yield stress of the tomato paste samples used in each test were not measured the Bingham yield stress was determined by extrapolation of the linear portion of the shear stress versus shear rate data to zero shear rates, as an approximation of the apparent static yield stress. Table 3 presents the Bingham yield stresses for each tomato paste sample determined using shear rates above $50 \mathrm{~s}^{-1}$ which corresponds to the range of shear rates in the plugging tests.

As reported in the literature apparent slip is a significant factor affecting the flow behavior of tomato concentrates [12]. If the tomato pastes are regarded as being Bingham plastics in which the apparent dynamic yield stress equals the Bingham yield stress the observation of creeping flow at shear stresses below the yield stress would be entirely due to apparent slip. This agrees with the statement that when the shear stress is less than the yield stress i.e. $\tau_{w} \tau_{0} \leq 1$ the bulk flow is negligible and the apparent motion is entirely due to the slipping of the paste [10].

\begin{tabular}{|c|c|c|c|c|c|c|c|}
\hline \multirow{2}{*}{ Test } & \multicolumn{3}{|c|}{ Pseudoplastic Model } & \multicolumn{4}{c|}{ Herschel-Bulkley Model } \\
\cline { 2 - 8 } & $\mathrm{m}$ & $\mathrm{n}$ & $\mathrm{R}^{2}$ & $\mathrm{~T}_{0}$ & $\mathrm{~m}$ & $\mathrm{n}$ & $\mathrm{R}^{2}$ \\
\cline { 2 - 8 } & $\mathrm{Pa-s}$ & --- & --- & $\mathrm{Pa}$ & $\mathrm{Pa}^{\mathrm{n}} \mathrm{s}^{\mathrm{n}}$ & --- & --- \\
\hline $\mathrm{T} 1$ & 171.2 & 0.138 & 0.954 & 150 & 48 & 0.264 & 0.969 \\
\hline $\mathrm{T} 2$ & 160.2 & 0.192 & 0.97 & 0 & 160.2 & 0.192 & 0.97 \\
\hline T3 & 195.7 & 0.146 & 0.969 & 0 & 195.7 & 0.146 & 0.969 \\
\hline T4 & 136.6 & 0.208 & 0.936 & 0 & 136.6 & 0.208 & 0.936 \\
\hline T5 & 121.1 & 0.192 & 0.959 & 0 & 121.1 & 0.192 & 0.959 \\
\hline T6 & 142.7 & 0.201 & 0.939 & 0 & 142.7 & 0.201 & 0.939 \\
\hline T7 & 100.6 & 0.26 & 0.994 & 69.5 & 38.4 & 0.404 & 0.999 \\
\hline
\end{tabular}

Table 2: Tomato paste rheological parameters.

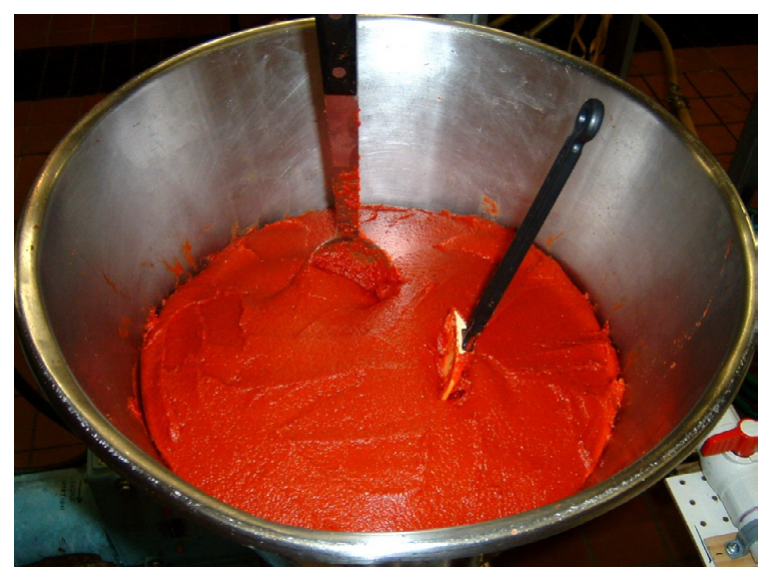

Figure 5: Tomato paste in the feed cone. 


\begin{tabular}{|c|c|c|c|c|}
\hline \multirow{2}{*}{ Test } & \multicolumn{4}{|c|}{ Bingham Plastic Model } \\
\cline { 2 - 5 } & $\mathrm{T}_{\mathrm{B}}$ & $\mathrm{m}$ & $\mathrm{n}$ & $\mathrm{R}^{2}$ \\
\hline & $\mathrm{Pa}$ & $\mathrm{Pa}^{\mathrm{n}}$ & --- & -- \\
\hline $\mathrm{T} 1$ & 323 & 0.122 & 1 & 0.902 \\
\hline $\mathrm{T} 2$ & 420 & 0.145 & 1 & 0.932 \\
\hline $\mathrm{T} 3$ & 397 & 0.139 & 1 & 0.967 \\
\hline $\mathrm{T} 4$ & 405 & 0.135 & 1 & 0.842 \\
\hline $\mathrm{T} 5$ & 343 & 0.1 & 1 & 0.982 \\
\hline $\mathrm{T} 6$ & 368 & 0.162 & 1 & 0.928 \\
\hline $\mathrm{T} 7$ & 251 & 0.66 & 1 & 0.973 \\
\hline
\end{tabular}

Table 3: Tomato paste-Bingham yield stress.

\begin{tabular}{|c|c|c|c|c|c|c|c|}
\hline \multirow{2}{*}{ Test } & \multirow{2}{*}{ Fluid } & \multirow{2}{*}{\begin{tabular}{|c|}
$\begin{array}{c}\text { Yield } \\
\text { Stress }\end{array}$ \\
$\mathrm{Pa}$
\end{tabular}} & \multicolumn{4}{|c|}{ Tube } & \multirow{2}{*}{$\begin{array}{l}\text { Plugged } \\
\text { Tubes }\end{array}$} \\
\hline & & & 1 & 2 & 3 & 4 & \\
\hline G1 & Glycerin & 0 & 0 & 0 & 0 & 0 & 0 \\
\hline G2 & Glycerin & 0 & 0 & 0 & 0 & 0 & 0 \\
\hline G3 & Glycerin & 0 & 0 & 0 & 0 & 0 & 0 \\
\hline $\mathrm{C} 2$ & Carbopol Gel & 86 & 1 & 1 & 0 & 0 & 2 \\
\hline $\mathrm{C} 1$ & Carbopol Gel & 104 & 1 & 1 & 0 & 0 & 2 \\
\hline $\mathrm{C} 3$ & Carbopol Gel & 106 & 1 & 1 & 0 & 1 & 3 \\
\hline $\mathrm{T} 7$ & Tomato Paste & 251 & 1 & 1 & 1 & 0 & 3 \\
\hline $\mathrm{T} 1$ & Tomato Paste & 323 & 1 & 0 & 1 & 1 & 3 \\
\hline $\mathrm{T} 5$ & Tomato Paste & 343 & 1 & 1 & 0 & 1 & 3 \\
\hline T6 & Tomato Paste & 368 & 1 & 1 & 0 & 1 & 3 \\
\hline T3 & Tomato Paste & 397 & 1 & 1 & 1 & 0 & 3 \\
\hline $\mathrm{T} 4$ & Tomato Paste & 405 & 1 & 1 & 1 & 0 & 3 \\
\hline $\mathrm{T} 2$ & Tomato Paste & 420 & 1 & 1 & 1 & 0 & 3 \\
\hline
\end{tabular}

1 = plugged tube; 0 = cleared tube

Table 4: Summary of test results.

This would also explain the observation made on tomato paste but not on Carbopol gel that after one tube had been cleared with flushing water the paste in the remaining tubes continued to creep slowly forward.

In the case of fluids such as tomato pastes in which slip occurs at shear stresses below the yield stress applying low shear stress would be expected to result in creeping flow of the paste. This means that in parallel-flow devices in which some tubes have been cleared by flushing with water and other tubes remain partially filled with paste material an extended period of pumping water through the cleared tubes would eventually clear the remaining tubes. However in a parallel-tube flow device such as a tubular heat exchanger flushing with water to clear tomato paste or other similar material from the tubes would be expected to be accomplished quickly. Unless the need is understood such extended flushing is unlikely to be performed. In this case the flow devices would not be fully cleared and the un-cleared tubes would be effectively plugged.

\section{Plugging experiment results}

As it can be seen in Table 4 in all tests run on yield-stress fluids two or three of the four parallel tubes remained plugged after flushing with water. In this table the yield stresses listed for the tomato paste tests are the Bingham yield stresses which are approximations of the apparent static yield stresses.

The following observations are based on the empirical results obtained in the plugging tests performed with the parallel-tube test rig. In all three tests using glycerin a viscous fluid with no yield stress all tubes were cleared with water. In all tests using fluids with a yield stress at least 2 of the 4 tubes were left partially filled with the yield stress fluid while the remaining tubes were completely cleared with water.

\section{Conclusions}

The cause of the formation of plugs in parallel-tube flow devices is explained. It has been shown that semi-solid fluids possessing a sufficient yield stress are not completely cleared from some parallel tubes when the device is flushed with water. The remaining tubes are effectively plugged. A solution to the problem of plugging is to slowly dilute the yield-stress process fluid during flushing gradually reducing its yield stress.

The experimental results lead to the following conclusions:

A. For plugging to occur the parallel tubes cannot have identical flow resistance.

B. For plugging to occur the fluid initially filling the tubes of a parallel-tube flow device must have a yield stress.

During normal operation plugging occurs only when the yield stress fluid is flushed with water or overly diluted process fluid.

\section{References}

1. Paseman R, Griffith $L$ (1987) Cleaning the tube side of heat exchangers Proceedings of the Fourth U.S. Water Jet Conference, Berkeley, CA.

2. Steffe JS (1996a) Rheological methods in food process engineering (2ndedn) Freeman Press, East Lansing, MI.

3. Barnes HA, Walters K (1985) The yield stress myth. Rheologica Acta 24: 323-326.

4. Hartnett JP, Hu RZ (1989) The yield stress-an engineering reality. J Rheology 33: $671-679$.

5. Chhabra RP, Richardson JF (1999) Non-Newtonian flow in the process industries. Butterworth-Heinemann, New York.

6. Rao MA (1999a) Rheology of fluid and semisolid foods; Principles and applications. Aspen Publishers, Gaithersburg.

7. Michaels YS, Bolger JC (1962) The plastic behavior of flocculated kaolin suspensions. Indus Eng Chem Fundamemtal 1: 152-162.

8. Qiu CG, Rao MA (1988) Role of pulp content and particle size in yield stress of apple sauce. J Food Sci 53: 1165-1170.

9. Lee Y, Bobroff S, Mc Carthy KL (2002) Rheological characterization of tomato concentrates and the effect on uniformity of processing. Chem Engi Commun 189: 339-351.

10. Meeker SP, Bonnecaze RT, Cloitre M (2004) Slip and flow in pastes of soft particles: direct observation and rheology. J Rheology 48: 1295-1320.

11. Mc Carthy KL, Kerr WL (1998) Rheological characterization of a model suspension during tube flow using MRI. J Food Engi 37: 11-23.

12. Dogan N, Mccarthy MJ, Powell RL (2002) In-line measurement of rheological parameters and modeling of apparent wall slip in diced tomato; Hydrodynamical behaviour of non- Newtonian flows in a cross-flow filtration tubular module. Exp Fluids 25: 243-253.

13. Ouriev B (2002) Investigation of the wall slip effect in highly concentrated disperse systems by means of non-invasive UVP-PD method in the pressure driven shear flow. J Colloid 64: 740-745.

14. Rao MA (1999b) Rheology of fluid and semisolid foods; principles and applications. Aspen Publishers, Gaithersburg.

15. Aguilera JM, Stanley DW (1999) Microstructural principles of food processing and engineering (2ndedn). Aspen Publishers, Gaithersburg.

16. Steffe JS (1996b) Rheological methods in food process engineering (2ndedn). Freeman Press, East Lansing, MI.

17. Carrere H, Rene F, Tanguy PA (2002) Properties of Carbopol solutions as models for yield-stress fluids. J Food Sci 67: 176-180.

18. Midoux N (1985) Mécanique et rhéologie des fluides en genie chimique. Éditions Tec and Doc Lavoisier, Paris.

19. Munson BR, Young DF, Okiishi TH (1998) Fundamentals of fluid mechanics (3rdedn). John Wiley \& Sons, New York. 
Citation: Steven Brandon C, Paul Dawson L (2016) Plugging of Parallel-Tube Devices with Fluid Foods. J Food Process Technol 7: 587. doi:10.4172/2157-7110.1000587

Page 7 of 7

20. Weats RC (1972) Handbook of chemistry and physics (53rdedn). Chemical Rubber Publishing, Cleveland, $\mathrm{OH}$.

21. Gilmount R (2002) Liquid viscosity correlations for flowmeter calculations. CEP Magazine 98: 37-41.
22. Curran SJ, Hayes RE, Afacan A, Williams MC (2002) In-line measurement of rheological parameters and modeling of apparent wall slip in diced tomato suspensions using ultrasonics. J Food Sci 67: 2235-2240.

23. Yoo B, Rao MA, Steffe JS (1995) Yield stress of food dispersions with vane method at controlled shear rate and shear stress. J Textur Studie 26: 1-10. 